\title{
Prediction and prevention of upper gastrointestinal bleeding after cardiac surgery: A case control study
}

\author{
Mamatha Bhat MD FRCPC ${ }^{1}$, Martin Larocque MD FRCPC ${ }^{1}$, Marcos Amorim MD ${ }^{1}$, \\ Karl Herba MD FRCPC ${ }^{1}$, Myriam Martel BSc ${ }^{1}$, Benoît De Varennes MD FRCSC ${ }^{2}$, Alan Barkun MD FRCPC ${ }^{1,3}$
}

\begin{abstract}
M Bhat, M Larocque, M Amorim, et al. Prediction and prevention of upper gastrointestinal bleeding after cardiac surgery: A case control study. Can J Gastroenterol 2012;26(6):340-344.
\end{abstract}

BACKGROUND: Gastrointestinal (GI) complications of cardiovascular surgery, particularly bleeding, occur frequently.

OBJECTIVE: To determine factors that predict upper GI bleeding (UGIB) after cardiac surgery to improve prognostication and, thus, outcomes.

METHODS: The present case-control study reviewed institutional records spanning 2002 to 2005 for consecutive patients who developed in-hospital UGIB following cardiovascular surgery. Each case was matched to two to three controls for age, sex and date of hospital admission. Demographics, pharmacotherapy (including use of in-hospital acid suppression), endoscopic findings and outcomes were recorded. After adjustment for possible confounders, including Parsonnet score and demographic parameters, conditional logistic regression analysis identified independent significant predictors of the subsequent development of UGIB.

RESULTS: The study population consisted of 131 cases (mean [ \pm SD] age $68.8 \pm 10.2$ years, $69.5 \%$ male, mean Parsonnet score $24.6 \pm 14.2)$ and 387 matched controls (mean age $68.8 \pm 10.8$ years, $70.0 \%$ male, mean Parsonnet score $20.9 \pm 14.2$ ). UGIB events occurred a mean of $10.3 \pm 7.7$ days after cardiac surgery. Duration of mechanical ventilation (OR 3.01 [95\% CI 1.44 to 6.28]), elevation of international normalized ratio (OR 1.91 [95\% CI 1.31 to 2.78]) and occurrence of Clostridium difficile colitis before bleeding (OR 3.15 [95\% CI 1.19 to 8.36]) were independent risk factors. Use of histamine type 2 receptor antagonists $\left(\mathrm{H}_{2} \mathrm{RAs}\right)$ (OR $0.65[95 \% \mathrm{CI}$ 0.38 to 1.12$]$ ) or proton pump inhibitors (PPIs) (OR 0.60 [95\% CI 0.27 to 1.32]) demonstrated trends toward protecting against UGIB after cardiac surgery.

CONCLUSIONS: GI bleeding events occurred approximately 10 days after cardiac surgery in patients with a complicated postoperative course. Significant predictors of subsequent bleeding included increased duration of mechanical ventilation and elevation of international normalized ratio; routine acid suppression with PPIs should be considered in such patients. $\mathrm{C}$ difficile colitis also significantly predicted UGIB, and $\mathrm{H}_{2}$ RAs should be considered for acid suppression. Neither $\mathrm{H}_{2} \mathrm{RAs}$ nor PPIs were effective in preventing UGIB, although the small number of patients limits definitive conclusions regarding the role of acid suppression.

Key Words: Cardiac surgery; $\mathrm{H}_{2}$ receptor antagonist; Perioperative prophylaxis; Proton pump inhibitors; Stress ulcer bleeding; Upper gastrointestinal bleeding

astrointestinal (GI) bleeding following cardiac surgery is uncommon

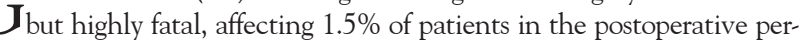
iod (1) with a mortality rate of up to $39 \%$. As cardiac surgery techniques have evolved over time, the patient population selected for surgery has become older and exhibits more comorbid illness (2). Old age, female sex, presence of diabetes and hypertension, and history of heart surgery and myocardial infarction were found to be predictors of increased risk for 30-day morbidity and mortality after coronary artery bypass graft surgery $(\mathrm{CABG})$ - the most common type of cardiac surgery (1).

\section{La prédiction et la prévention des saignements œsogastroduodénaux après une opération cardiaque : une étude cas-témoins}

HISTORIQUE : Les complications gastro-intestinales (GI) sont fréquentes en chirurgie cardiovasculaire, notamment les saignements.

OBJECTIF : Déterminer les facteurs qui permettent de prédire un saignement œesogastroduodénal (SOGDD) après une chirurgie cardiaque pour améliorer le pronostic et donc, les issues.

MÉTHODOLOGIE : Les auteurs de la présente étude cas-témoins ont analysé les dossiers institutionnels de patients consécutifs qui ont présenté un SOGDD en milieu hospitalier après une opération cardiovasculaire entre 2002 et 2005. Ils ont apparié chaque cas à deux ou trois témoins selon l'âge, le sexe et la date d'hospitalisation. Ils ont consigné les données démographiques, la pharmacothérapie (y compris l'utilisation de suppression acide en milieu hospitalier), les résultats endoscopiques et les issues. Après rajustement compte tenu des variables confusionnelles possibles, y compris l'indice de Parsonnet et les paramètres démographiques, l'analyse de régression logistique a permis d'établir d'importants prédicteurs indépendants d'apparition ultérieure de SOGDD.

RÉSULTATS : La population à l'étude se composait de 131 cas (âge moyen [ \pm ÉT] de 68,8 $\pm 10,2$ ans, $69,5 \%$ d'hommes, indice de Parsonnet moyen de $24,6 \pm 14,2$ ) et de 387 sujets témoins appariés (âge moyen de $68,8 \pm 10,8$ ans, $70,0 \%$ d'hommes, indice de Parsonnet moyen de 20,9 $\pm 14,2$ ). Les SOGDD se sont produits en moyenne $10,3 \pm 7,7$ jours après l'opération cardiaque. La durée de la ventilation mécanique (RRR 3,01 [95 \% IC 1,44 à 6.28]), l'élévation du rapport international normalisé (RRR 1,91 [95\% IC 1,31 à 2,78]) et l'occurrence de colite à Clostridium difficile avant le saignement (RRR 3,15 [95 \% IC 1,19 à 8,36]) étaient des facteurs de risque indépendants. Lutilisation d'antagonistes des récepteurs à l'histamine de type $2\left(\mathrm{ARH}_{2}\right)$ (RRR 0,65 [95 \% IC 0,38 à 1,12]) ou des inhibiteurs de la pompe à protons (IPP) (RRR 0,60 [95\% IC 0,27 à 1,32]) a démontré des tendances vers la protection des SOGDD après une opération cardiaque.

CONCLUSIONS : Les saignements GI se produisaient une dizaine de jours après l'opération cardiaque chez les patients ayant une évolution postopératoire complexe. Les prédicteurs importants de saignement ultérieur incluaient une ventilation mécanique de plus longue durée et une élévation du rapport international normalisé. La suppression systématique d'acide par les IPP pourrait être envisagée chez ces patients. La colite à $\mathrm{C}$ difficile était également un prédicteur important de SOGDD; on pourrait alors envisager les $\mathrm{ARH}_{2}$ pour la suppression acide. $\mathrm{Ni}$ les $\mathrm{ARH}_{2}$ ni les IPP n'étaient efficaces pour prévenir les SOGDD, même si le petit nombre de patients empêche de tirer des conclusions définitives quant au rôle de la suppression acide.

Although stress ulcers and upper GI bleeding (UGIB) following cardiac surgery have been reported in retrospective studies since 1957 (3), independent risk factors and the respective roles of histamine type 2 receptor antagonists $\left(\mathrm{H}_{2} \mathrm{RA}\right)$ and proton pump inhibitors $(\mathrm{PPI})$ in this setting to reduce UGIB remain poorly characterized.

Accordingly, the goal of the present study was to assess the factors predicting the occurrence of UGIB after cardiac surgery, and whether the in-hospital use of acid suppression (with $\mathrm{H}_{2} \mathrm{RA}$ or PPI) in patients undergoing cardiovascular surgery effectively prevents these events.

\footnotetext{
${ }^{1}$ Division of Gastroenterology; ${ }^{2}$ Division of Cardiothoracic Surgery; ${ }^{3}$ Division of Clinical Epidemiology, McGill University and the McGill University Health Centre, Montreal, Quebec

Correspondence: Dr Alan Barkun, Division of Gastroenterology, The McGill University Health Centre, Montreal General Hospital site, 1650 Cedar Avenue, Room D16.125, Montreal, Quebec H3G 1A4. Telephone 514-934-8309, fax 514-834-8531, e-mail alan.barkun@muhc.mcgill.ca Received for publication May 9, 2011. Accepted September 6, 2011
} 


\section{METHODS}

\section{Study population and identification of cases and controls}

The present case-control study was conducted at the McGill University Health Centre, a tertiary care institution located in Montreal, Quebec. All patients who developed acute UGIB after cardiac surgery on the cardiac ward or intensive care unit between January 2002 and April 2005 were included. These cases were identified using a cardiac surgery database of patients who underwent various forms of cardiac surgery during this period. These surgeries primarily included CABG, but also valve replacement, heart transplant and ventricular assist device placement. All patients had been operated on by the same surgeon. UGIB was defined as an in-hospital episode of overt hematemesis, coffee-ground emesis, melena, hematochezia or a combination thereof (4). Patients whose UGIB was due to bleeding varices, identified on endoscopy, were excluded from the present study. Patients with clinically significant UGIB underwent gastroscopy. Each case of UGIB was matched with two or three controls to support statistical adequacy. The matching criteria were postcardiac surgery patients who did not experience bleeding, age within a five-year range, sex, and date of admission within 180 days (to minimize variability attributable to disparities in supportive management over time).

\section{Sources of clinical information}

The clinical information was abstracted from different sources. Patient characteristics before the UGIB event included mechanical ventilation $>48 \mathrm{~h}$, elevated international normalized ratio (INR), platelet count and prothrombin time as recorded in a prospectively collected cardiac surgery database. On admission, and in a separate divisional registry, the treating surgeon also prospectively collected the variables that comprise the Parsonnet score (5), a widely recognized postcardiovascular surgery outcomes predictive scale that includes age, morbid obesity, congestive heart failure, preoperative intra-aortic balloon pump, severe chronic obstructive pulmonary disease, reoperation, diabetes, cardiac ejection fraction, single valvular surgery (either aortic or mitral), valvular and aortocoronary bypass surgery, hypertension, left main artery disease and special conditions. A Parsonnet score of 0 to 4 is associated with a predicted mortality rate of $1 \%$, whereas a score of $\geq 20$ is associated with a mortality rate $>30 \%$ (5).

The institutional pharmacy database provided medication dispensing information $\left(\mathrm{H}_{2} \mathrm{RA}\right.$, PPI, acetylsalicylic acid, nonsteroidal anti-inflammatory medications, antiplatelet agents including clopidogrel, and anticoagulants such as warfarin, unfractionated heparin and low-molecular-weight heparin). Specifically investigated was $\mathrm{H}_{2} \mathrm{RA}$ and PPI use starting on the date of hospital admission until the date of UGIB for cases, and throughout hospitalization for controls. The presence of anticoagulant and antiplatelet medications was also tested for a possible association with UGIB. Additional patient information collected from the hospital chart included the development of major postoperative complications such as Clostridium difficile colitis (toxin and culture proven), renal failure secondary to acute tubular necrosis, bowel ischemia (intestinal mucosal damage caused by inadequate blood supply), mediastinitis (documented infection of the mediastinum) and mortality. These postoperative complications were documented in all controls and in cases only if they had occurred before the UGIB event. All baseline characteristics (eg, historical, physical and laboratory values) were recorded preoperatively for cases and controls. All other variables were recorded postoperatively, before the UGIB incident for cases or during admission for the controls.

\section{Statistical analysis}

Baseline clinical characteristics and outcomes were analyzed descriptively for both UGIB cases and controls. Continuous variables were reported as SDs (or median and ranges, where appropriate), with a Wilcoxon nonparametric test to explore a possible association with UGIB. Categorical variables were reported as proportions and $95 \%$ CIs, with inferential analysis performed using $\chi^{2}$ testing.
Possible factors predicting UGIB were selected from a list of variables based on clinical relevance among baseline patient characteristics, pharmacological therapies and postcardiac surgery complications. Multivariable models to identify possible independent significant clinical predictors of bleeding were specifically created. Conditional logistic regression analysis was performed, yielding ORs for the various parameters assessed. Only variables associated with $\mathrm{P}<0.15$ were considered for inclusion in the model. Variables were excluded using a stepwise selection approach. A level of significance of 0.05 was adopted for all inferential testing. All analyses were performed using SAS version 9.2 (SAS Institute, USA).

\section{Baseline characteristics}

\section{RESULTS}

Data for the study population spanned 2002 to 2005, and included 131 cases and 387 matched controls. Cases and controls were appropriately matched for age and sex (mean [ \pm SD] age $68.8 \pm 10.2$ years, $69.5 \%$ male for cases, versus $68.8 \pm 10.8$ years, $70.0 \%$ male, for controls). There were significant differences between the two groups with regard to Parsonnet score, mechanical ventilation $>48 \mathrm{~h}$, INR, prothrombin time and warfarin use. UGIB cases had a higher mean Parsonnet score than controls $(24.6 \pm 14.2$ versus $20.9 \pm 14.2$, respectively); however, this difference was not clinically significant given the high mortality rate associated with a Parsonnet score $\geq 20$ (Table 1).

The average number of days between the surgery and the onset of UGIB was $10.3 \pm 7.7$ days. There were no differences in the in-hospital use of $\mathrm{H}_{2} \mathrm{RA}$ or PPI between cases and controls, with $45.0 \%$ (95\% CI (36.4\% to $53.7 \%$ ) versus $46.0 \%$ (95\% CI $41.0 \%$ to $51.0 \%$ ) ( $\mathrm{P}=0.85$ ); and $16.8 \%$ (95\% CI $10.3 \%$ to $23.3 \%$ ) versus $17.8 \%$ (95\% CI $14.0 \%$ to 21.7) $(\mathrm{P}=0.79)$, respectively (Table 1$)$.

Among cases given PPIs in hospital, the median duration of administration was two days (range one to 65 days), with a median dosage of $40 \mathrm{mg}$ (range $40 \mathrm{mg}$ to $272 \mathrm{mg}$ ). Among cases given in-hospital $\mathrm{H}_{2} \mathrm{RA}$, the median number of days of administration was three (range one to 66 days), with a median dosage of $40 \mathrm{mg}$ (range $20 \mathrm{mg}$ to $300 \mathrm{mg}$ ). The elapsed time from admission to first prescription of $\mathrm{H}_{2} \mathrm{RA}$ was $4.1 \pm 6.0$ days, and $7.2 \pm 7.9$ days for PPIs.

\section{Episodes of UGIB}

Presenting symptoms of bleeding among cases included melena $(59.4 \%)$, coffee ground emesis $(33.3 \%)$, hematochezia $(13.2 \%)$ and hematemesis $(11.6 \%)$. Initial hemodynamic instability at bleeding was noted in $47.1 \%$ of cases.

Cases were transfused with a median of 3.0 units (range 2.0 to 6.0 units) of packed red blood cells. Endoscopy was performed in 122 of the 131 patients. Of these 122 patients, $85.5 \%$ had ulcers as the cause of UGIB (45.9\% duodenal, $22.5 \%$ gastric, $9.2 \%$ esophageal, multiple sites in 22.4\%). Other etiologies of UGIB included esophagitis, erosions, Dieulafoy lesions and Mallory-Weiss tears (6).

\section{Postoperative course and complications other than bleeding}

Among cases of UGIB, the median length of stay was 24.0 days (range 14.0 to 47.0 days) with a median intensive care unit stay of 4.0 days (range 1.0 to 12.0 days). Major postoperative complications other than bleeding included the development of $\mathrm{C}$ difficile colitis, renal failure secondary to acute tubular necrosis requiring dialysis, congestive heart failure, bowel ischemia and mediastinitis (Table 2). Overall mortality was $19.1 \%$ among cases and $10.1 \%$ among control patients.

\section{Outcomes and predictive modelling}

The in-hospital administration of neither an $\mathrm{H}_{2} \mathrm{RA}$ (OR 0.65 [95\% Cl 0.38 to 1.12$]$ ) nor a PPI (OR 0.60 [95\% CI 0.27 to 1.32$]$ ) was significantly associated with the subsequent development of UGIB. The Parsonnet score (OR 1.01 [95\% CI 0.99 to 1.03]) was not a significant predictor of UGIB as a whole. An elevated INR (OR 1.91 [95\%Cl 1.31 to 2.78$]$ ), a need for mechanical ventilation $>48$ h (OR 3.01 [95\% 
TABLE 1

Clinical characteristics of cases and controls

\begin{tabular}{|c|c|c|c|}
\hline Variable & Cases $^{*}(n=131)$ & Controls $^{\dagger}(n=387)$ & $\mathbf{P}$ \\
\hline Age, years, mean \pm SD & $68.8 \pm 10.2$ & $68.8 \pm 10.8$ & 0.784 \\
\hline Male sex & $69.5(61.5-77.5)$ & $70.0(65.4-74.6)$ & 0.913 \\
\hline Parsonnet score ${ }^{\ddagger}$, mean \pm SD & $24.6 \pm 14.2$ & $20.9 \pm 14.2$ & 0.005 \\
\hline International normalized ratio, mean \pm SD & $1.71 \pm 1.60$ & $1.28 \pm 0.58$ & $<0.001$ \\
\hline Prothrombin time, $\mathrm{s}$, mean $\pm \mathrm{SD}$ & $53.3 \pm 35.6$ & $52.9 \pm 39.3$ & 0.034 \\
\hline Platelet count, $\times 10^{9} / \mathrm{L}$, mean $\pm \mathrm{SD}$ & $243.5 \pm 132.9$ & $239.3 \pm 108.2$ & 0.057 \\
\hline Nonsteroidal anti-inflammatory drugs & $42.0(33.4-50.5)$ & $38.4(33.6-43.3)$ & 0.471 \\
\hline Clopidogrel & $22.9(15.6-30.2)$ & $20.0(16.0-24.0)$ & 0.533 \\
\hline Warfarin & $48.1(39.4-56.8)$ & $25.5(21.1-29.8)$ & $<0.001$ \\
\hline Unfractionated heparin & $95.4(91.8-99.0)$ & $96.6(98.4-94.8)$ & 0.591 \\
\hline Low-molecular-weight heparin & $6.9(2.5-11.3)$ & $6.8(4.2-9.3)$ & 0.999 \\
\hline Histamine type 2 receptor antagonist & $45.0(36.4-53.7)$ & $46.0(41.0-51.0)$ & 0.849 \\
\hline
\end{tabular}

Data presented as \% (95\% Cl) unless otherwise indicated. ${ }^{*}$ Patients who developed upper gastrointestinal bleeding postcardiac surgery; ${ }^{\dagger}$ Age- and sex-matched patients who did not experience bleeding postcardiac surgery; ${ }^{\ddagger}$ Standard scoring system used in cardiac surgery preoperative evaluation to estimate the risk of postoperative complications

\section{TABLE 2}

Incidence of postoperative complications among cases of upper gastrointestinal bleeding versus matched controls

\begin{tabular}{lcc}
\hline Complication & Cases & Controls \\
\hline Clostridium difficile colitis & $13.0(7.2-18.8)$ & $3.6(1.8-5.5)$ \\
Acute tubular necrosis/dialysis & $16.8(10.3-23.2)$ & $5.9(3.6-8.3)$ \\
Congestive heart failure & $47.9(38.9-57.0)$ & $33.7(28.9-38.5)$ \\
Bowel ischemia & $8.4(3.6-13.2)$ & $1.8(0.5-3.1)$ \\
Mediastinitis & $6.9(2.5-11.3)$ & $1.0(0-2.1)$ \\
\hline
\end{tabular}

Data presented as \% (95\% Cl)

CI 1.44 to 6.28]), and the development of postoperative $C$ difficile colitis before bleeding (OR 3.15 [95\%CI 1.19 to 8.36]) were significant predictors of UGIB (Table 3 ).

\section{DISCUSSION}

We sought to determine factors predictive of UGIB following cardiac surgery, and whether using perioperative acid suppression in patients undergoing cardiac surgery could play a preventive role. These are clinically important questions given the relatively high prevalence of UGIB as a complication and significant associated morbidity and mortality. Patients undergoing cardiac surgery experience relative ischemia in the gut during bypass time, are hypocoagulable perioperatively due to induced hypothermia, and are given anticoagulation and antiplatelet agents during the postoperative period (7).

Several studies have sought to determine the factors predictive of GI complications post-CABG surgery. A study by Yoshida et al (8) determined that certain baseline patient characteristics, such as age $>70$ years, diabetes mellitus, history of renal failure or cerebrovascular disease and postoperative low cardiac output syndrome, predicted postoperative GI complications as a whole (UGIB, enterocolitis and ischemic colitis). These predictors have been confirmed by other groups (9-12). Additional risk factors have included advanced arteriosclerosis, the need for hemodialysis, intra-aortic balloon pump, concomitant valve surgery and procedure urgency (13). On-pump versus off-pump CABG has not been found to correlate with adverse GI outcomes (14); however, prolonged cardiopulmonary bypass ( $>98 \mathrm{~min}$ ) has been identified as a risk factor for UGIB. Another study investigating GI complications post-CABG found that off-pump and on-pump bypass surgeries differed with respect to the type of postoperative GI complication: bowel ischemia was associated with the need for onpump CABG, while GI bleeding was associated with its absence (15).

\section{TABLE 3}

Significant predictors of upper gastrointestinal bleeding

\begin{tabular}{lc}
\hline Variable & OR $(95 \% \mathrm{Cl})$ \\
\hline Mechanical ventilation $>48 \mathrm{~h}$ & $3.01(1.44-6.28)$ \\
Elevated international normalized ratio & $1.91(1.31-2.78)$ \\
Clostridium difficile colitis & $3.15(1.19-8.36)$ \\
\hline
\end{tabular}

Given that mortality rates associated with UGIB in this patient population reach $38.5 \%(7)$, there have been attempts to evaluate the role of gastric acid suppression on the prevention of UGIB following cardiac surgery. This therapeutic approach is based on favourable outcomes in peptic ulcer bleeding $(16,17)$, in which profound acid suppression is believed to favour clot stabilization, platelet aggregation and local healing (17-20), and in the prevention of stress ulcer bleeding, which is discussed below. Concerns with such an approach have stemmed from the observed association linking $C$ difficile colitis to PPI use (21). In fact, the period of our analysis (2002 to 2005) corresponds with a period antedating and encompassing the onset of widespread reluctance to prescribe PPIs given the small but real published associated risk of $\mathrm{C}$ difficile. This is the reason for our having chosen this time frame because it served as a natural experiment for our particular study question.

Studies performed before the advent of PPIs revealed no difference in rates of UGIB comparing patients on $\mathrm{H}_{2} \mathrm{RA}$ with subjects receiving antacids or controls $(0.35 \%$ versus $0.45 \% ; \mathrm{P}=0.16)(20,22)$. A more recent time series noted a decreased incidence in GI complications as a whole (encompassing UGIB and ischemic bowel) from 1.3\% (1998 to 2001 ) to $0.7 \%$ (2002 to 2004) $(\mathrm{P}=0.04)(23)$, attributed to improved intraoperative measures and a systematic policy of perioperative ulcer prophylaxis with $\mathrm{H}_{2} \mathrm{RA}$ and PPIs.

Our broad case definition of UGIB was adopted because of the heterogeneity in definitions used in the literature pertaining to stress ulcer bleeding (24). The three variables we identified as significant risk factors for UGIB were mechanical ventilation $>48 \mathrm{~h}$, an elevated INR and the occurrence of $\mathrm{C}$ difficile colitis. These factors reflect a more severe postoperative course serving as a potentiator of UGIB events. Both cases and controls had an elevated Parsonnet score associated with a mortality rate $>30 \%$, reflecting the heavy comorbid burden in the cardiac surgery population at our institution. The Parsonnet score, although reflective of a complicated patient substrate, has not been found to increase the risk of GI complications as 
a whole (25). On the other hand, studies by Sanisoglu et al (7) and Musleh et al (14) correlated the Euroscore - a reflection of a patient's predicted operative mortality - with risk of GI complications.

Focusing specifically on UGIB complications, we determined that the in-hospital use of $\mathrm{H}_{2} \mathrm{RA}$ or PPI did not significantly alter the postoperative occurrence of UGIB, although trends were noted for both exposures. The UGIB events occurred, on average, 10 days after the surgery, with no significant difference between the use of acid suppression among case patients before the UGIB episode compared with control patients throughout their hospitalization. Although possibly due to a lack of statistical power, we postulate that the lack of observed significant difference may also be attributable to pathophysiological changes other than those that were $\mathrm{pH}$ related, favouring stress ulcer formation among cardiac surgery patients with a complicated postoperative course. Such physiological changes include splanchnic hypoperfusion, decreased bicarbonate production, decreased emptying of gastric acid due to hypomotility, vasoconstricting catecholamine release, barrier disruption and bacterial overgrowth (26). Others have also failed to demonstrate a benefit attributable to preoperative acid suppression with regard to the risk of UGIB (27).

The efficacy of both $\mathrm{H}_{2} \mathrm{RA}$ and PPI in a stress ulcer bleeding prophylaxis setting has been shown in other critical care populations $(4,28-31)$.

The case-control design of the present study limits any definitive conclusions on therapeutic associations and outcomes. We attempted to match patients according to three broad demographic criteria, with controls being subjected to measurable exposures that rendered them at risk of becoming cases (32). The optimal study design for our clinical question would have been an adequately powered randomized controlled trial. Furthermore, it would have been of interest to specifically document the duration of $\mathrm{PPI} / \mathrm{H}_{2} \mathrm{RA}$ intake before hospitalization, which would have permitted a more precise stratification of

\section{REFERENCES}

1. Nalysnyk L, Fahrbach K, Reynolds MW, Zhao SZ, Ross S. Adverse events in coronary artery bypass graft (CABG) trials: A systematic review and analysis. Heart 2003;89:767-72.

2. Mangano DT, Siliciano D, Hollenberg M, et al. Postoperative myocardial ischemia. Therapeutic trials using intensive analgesia following surgery. The Study of Perioperative Ischemia (SPI) Research Group. Anesthesiology 1992;76:342-53.

3. Berkowitz D, Wagner BM, Uricchio JF. Acute peptic ulceration following cardiac surgery. Ann Intern Med 1957;46:1015-23.

4. Cook D, Guyatt G, Marshall J, et al. A comparison of sucralfate and ranitidine for the prevention of upper gastrointestinal bleeding in patients requiring mechanical ventilation. New Engl J Med 1998;338:791-7.

5. Bernstein AD, Parsonnet V. Bedside estimation of risk as an aid for decision-making in cardiac surgery. Ann Thorac Surg 2000;69:823-8.

6. Amorim M, Barkun A, Larocque M, Herba K, Devarennes B, Martel M. Non variceal upper gastrointestinal bleeding (UGIB) following cardiac surgery: Patient characteristics, endoscopic lesions and prognosis. Gastrointest Endosc 2007;65:A158 (Abst).

7. Sanisoglu I, Guden M, Bayramoglu Z, et al. Does off-pump CABG reduce gastrointestinal complications? Ann Thorac Surg 2004;77:619-25.

8. Yoshida K, Matsumoto M, Sugita T, et al. Gastrointestinal complications in patients undergoing coronary artery bypass grafting. Ann Thorac Cardiovasc Surg 2005;11:25-8.

9. Krasna M, Flancbaum L, Trooskin S, et al. Gastrointestinal complications after cardiac surgery. Surgery 1988;104:773-80.

10. Aouifi A, Piriou V, Bastien O, et al. Complications digestives sévères après chirurgie cardiaque sous circulation extracorporelle. Can J Anesth 1999;46:114-21.

11. Byhahn C, Strouhal U, Martens S, Mierdl S, Kessler P, Westphal K. Incidence of gastrointestinal complications in cardiopulmonary bypass patients. World J Surg 2001;25:1140-4.

12. Norton I, Pokorny C, Baird D, Selby W. Upper gastrointestinal haemorrhage following coronary artery bypass grafting. Intern Med J 2008;25:297-301. patients with potentially greater protection against UGIB; however, the objective was to focus particularly on the in-hospital use of these medications. Another factor to consider is the presence of bowel wall edema among cardiac surgery patients, which could impair the effect of oral compared with intravenous acid suppression administration. As discussed briefly above, although our study comprised a significant number of patients as an optimally designed case-control study, conclusions are limited by statistical power given the relatively small number of patients on in-hospital PPI or $\mathrm{H}_{2} \mathrm{RA}$; however, the point estimates of acid suppressants intake was very similar among cases and controls. Helicobacter pylori serological status was not systematically investigated, but its presence has not been shown to influence UGIB post-CABG in patients receiving stress ulcer prophylaxis (33).

UGIB is an important clinical problem after CABG surgery, most oftern occurring 10 days postoperatively and entailing significant morbidity and mortality. Routine perioperative in-hospital acid suppression was not effective in preventing UGIB after cardiac surgery, perhaps because of the role of nonacid-related physiological factors leading to mucosal breakdown and hemorrhage in this context, or lack of statistical power to demonstrate a modest benefit. Risk factors for subsequent bleeding include duration of mechanical ventilation, an elevated INR and the occurrence of $\mathrm{C}$ difficile infection. Treating physicians should consider routinely giving acid suppression prophylactically to patients with these risk factors (ie, PPIs to those intubated for a longer period and high INR, and $\mathrm{H}_{2} \mathrm{RAs}$ to patients with $\mathrm{C}$ difficile colitis) after cardiac surgery. Additional research is needed to validate these biologically plausible findings and determine whether acid suppression in a subgroup of patients with these characteristics may be useful.

DISCLOSURES: Dr Barkun is a Research Scholar (Chercheur National) of the Fonds de la Recherche en Santé du Québec.

13. Rodriguez F, Nguyen T, Galanko J, Morton J. Gastrointestinal complications after coronary artery bypass grafting: A national study of morbidity and mortality predictors. J Am Coll Surg 2007;205:741-7.

14. Musleh G, Patel N, Grayson A, et al. Off-pump coronary artery bypass surgery does not reduce gastrointestinal complications. Eur J Cardio Thorac Surg 2003;23:170-4.

15. Croome K, Kiaii B, Fox S, Quantz M, McKenzie N, Novick R. Comparison of gastrointestinal complications in on-pump versus off-pump coronary artery bypass grafting. Can J Surg 2009;52:125.

16. Dorward S, Sreedharan A, Leontiadis G, Howden C, Moayyedi P, Forman D. Proton pump inhibitor treatment initiated prior to endoscopic diagnosis in upper gastrointestinal bleeding. Cochrane Database Syst Rev2006;(4):005415.

17. Gralnek I, Barkun A, Bardou M. Management of acute bleeding from a peptic ulcer. New Engl J Med 2008;359:928-37.

18. Barkun A, Bardou M, Marshall J. Consensus recommendations for managing patients with nonvariceal upper gastrointestinal bleeding. Ann Intern Med 2003;139:843-57.

19. Barkun C, Plourde F. Review article: Acid suppression in non-variceal acute upper gastrointestinal bleeding. Aliment Pharmacol Therap 2001;131565-84.

20. van der Voort P, Zandstra D. Pathogenesis, risk factors, and incidence of upper gastrointestinal bleeding after cardiac surgery: Is specific prophylaxis in routine bypass procedures needed? J Cardiothorac Vascul Anesth 2000;14:293-9.

21. Leonard J, Marshall J, Moayyedi P. Systematic review of the risk of enteric infection in patients taking acid suppression. Am J Gastroenterol 2007;102:2047-56.

22. Rosen H, Vlahkes G, Rattner D. Fulminant peptic ulcer disease in cardiac surgical patients: Pathogenesis, prevention, and management. Crit Care Med 1992;20:354-9.

23. Filsoufi F, Rahmanian P, Castillo J, Scurlock C, Legnani P, Adams D. Predictors and outcome of gastrointestinal complications in patients undergoing cardiac surgery. Ann Surg 2007;246:323-9.

24. Ali T, Harty RF. Stress-induced ulcer bleeding in critically ill patients. Gastroenterol Clin North Am 2009;38:245-65. 
25. Raja S, Haider Z, Ahmad M. Predictors of gastrointestinal complications after conventional and beating heart coronary surgery. The Surgeon 2003;1:221-8.

26. Schmidt H, Martindale R. The gastrointestinal tract in critical illness: Nutritional implications. Curr Opin Clin Nutr Metab Care 2003;6:587-91.

27. Ait $\mathrm{H}$, Selkane C, Moutaki A, eds. Upper digestive bleedings after cardiac surgery. Ann Caardiol Angiol (Paris) 2007:126-9.

28. Somberg L, Morris J Jr, Fantus R, et al. Intermittent intravenous pantoprazole and continuous cimetidine infusion: Effect on gastric $\mathrm{pH}$ control in critically ill patients at risk of developing stressrelated mucosal disease. J Trauma 2008;64:1202-10.

29. Conrad S, Gabrielli A, Margolis B, et al. Randomized, double-blind comparison of immediate-release omeprazole oral suspension versus intravenous cimetidine for the prevention of upper gastrointestinal bleeding in critically ill patients. Crit Care Med 2005;33:760-5.

30. Kantorova I, Svoboda P, Scheer P, et al. Stress ulcer prophylaxis in critically ill patients: A randomized controlled trial. Hepato-gastroenterol 2004;51:757-61.

31. Levy M, Seelig C, Robinson N, Ranney J. Comparison of omeprazole and ranitidine for stress ulcer prophylaxis. Dig Dis Sci 1997;42:1255-9.

32. Coggon D, Rose G, Barker D. Epidemiology for the uninitiated, 15th edn. London: BMJ Books, 2003:73.

33. Halm U, Halm F, Thein D, Mohr F, Mössner J. Helicobacter pylori infection: A risk factor for upper gastrointestinal bleeding after cardiac surgery? Crit Care Med 2000;28:110-3. 


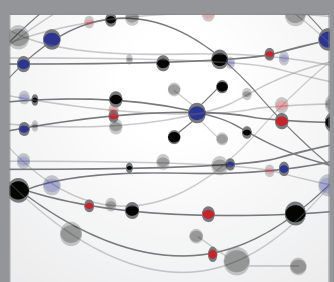

The Scientific World Journal
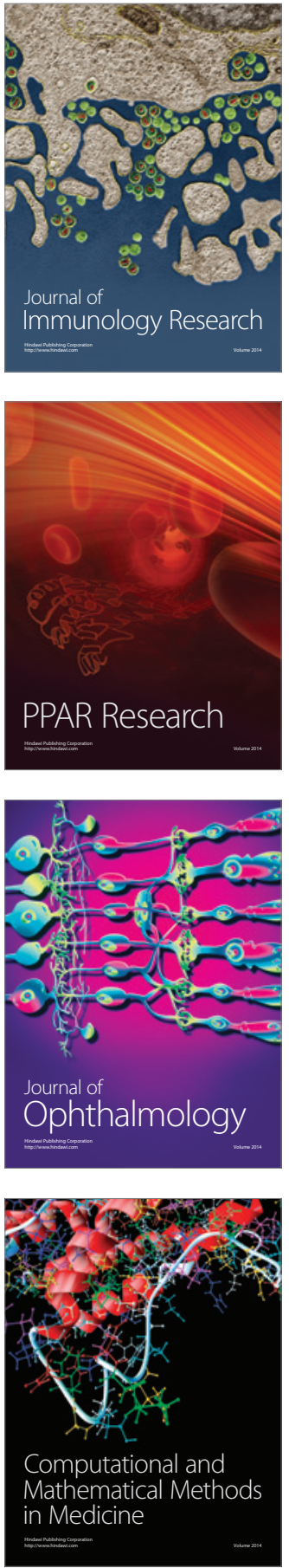

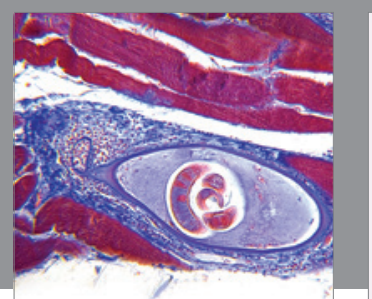

Gastroenterology Research and Practice

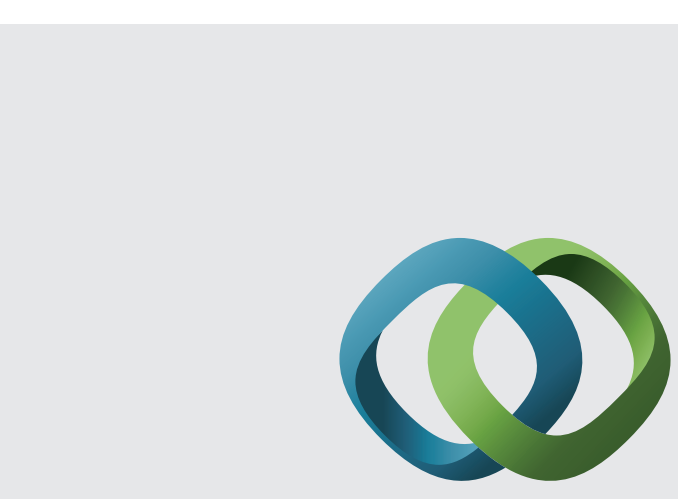

\section{Hindawi}

Submit your manuscripts at

http://www.hindawi.com
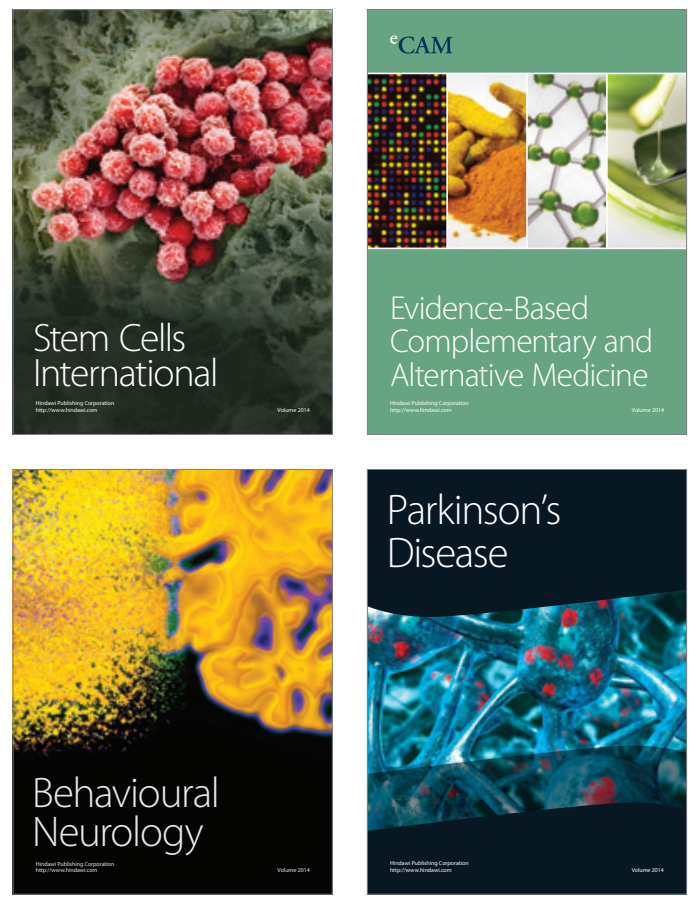
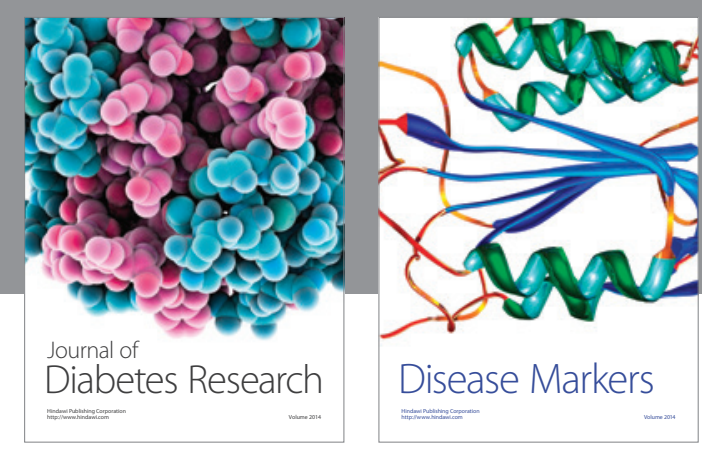

Disease Markers
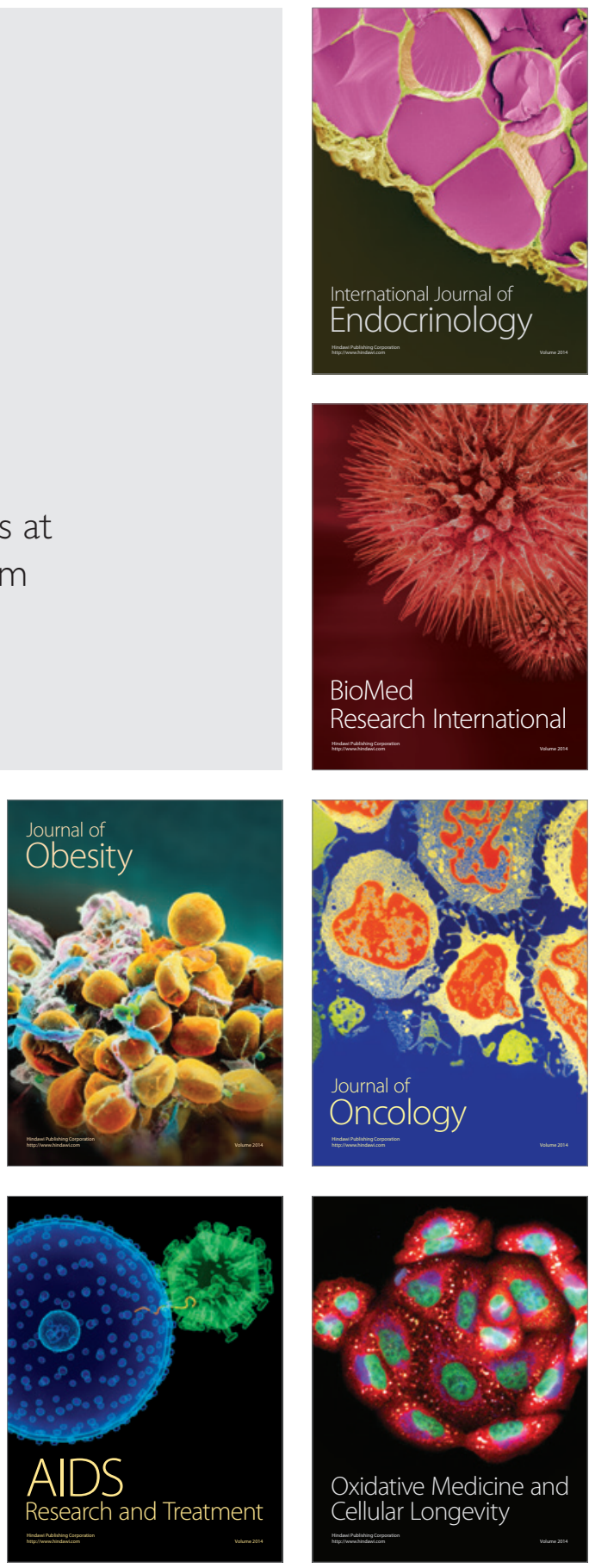